\title{
Aportación al estudio de las rentas provinciales de la Galicia del Antiguo Régimen
}

\author{
Pegerto SaAvedra *
}

Las diversas monografias que se han venido realizando sobre la Galicia del Antiguo Régimen coinciden en destacar el escaso peso que tanto, en términos absolutos como relativos, suponían para el campesinado las exacciones de la fiscalidad real. Los datos de que se dispone, de diferentes comarcas, son bastante contundentes al respecto, y prueban que, en la total de las diversas cargas que satisfacía el campesinado, a la Hacienda Real en concepto de rentas provinciales le correspondía siempre menos del 10 por 100 , e incluso menos del 5 por 100 en muchas feligresías. No obstante, si en vez de atender a los datos de comarcas concretas, utilizamos las cifras globales con que es posible contar para todo el Reino de Galicia, los resultados varian bastante, lo que no significa que las afirmaciones contenidas en las varias monografías sean falsas. Ocurre que los trabajos monográficos se ocupan, en general, del mundo rural, mientras que la fiscalidad real, como inmediatamente vamos a ver, tenía un marcado carácter urbano, igual que sucedía en el resto de la corona de Castilla.

Los datos con que contamos para mediados del siglo XVIII son bastante significativos. Las rentas provinciales -exceptuando las enajenadas- según la contabilidad del Archivo General de Simancas, ascendian en 1775 a unos 6,76 millones de reales, en tanto el diezmo lo valora el Catastro de Ensenada en 9,65 millones, y las rentas forales en 12,4 millones. La ventaja de diezmos y foros sobre las rentas provinciales es considerable, pero éstas no son en absoluto despreciables, pues reuniendo en un montón rentas provinciales, diezmos y rentas forales, las

* Universidad de Santiago de Compostela. 
primeras suponian casi una cuarta parte (el $23,4 \%$ ) del total '. Este es, sin duda, un cálculo tosco, por cuanto habría que computar el excedente generado por vía de arriendos (que no aparece en los Mapas Generales del Castastro), los censos, Voto de Santiago...; habria que tener en cuenta, además, la probable infravaloración de los foros $y$, sobre todo, de los diezmos; las rentas forales por haberse evaluado en dinero a unos precios bajos y los diezmos por los mismo y porque se ven afectados por la ocultación de superficies y calidades de tierra ${ }^{2}$. Nos parece que el diezmo está infravalorado por lo menos en un 50 por 100 y que cuando se realiza el Catastro de Ensenada el excedente generado por la vía decimal era más cuantioso que el extraído en concepto de rentas forales, no porque las pensiones forales fuesen, por término medio, inferiores al diezmo - lo que circunstancialmente podía suceder- sino porque no había, salvo excepciones muy contadas, tierras exentas de esta última carga y sí las había libres de canon foral o arrendaticio. Añadamos a este respecto, y a modo de inciso, que la infravaloración del diezmo enmascara la elevada participación de la iglesia en el reparto del excedente agrario: hacia 1750 a los eclesiásticos les corresponderían dos tercios del total de rentas forales y decimales (pues perciben el $94 \%$ de éstas y el $46 \%$ de aquéllas), o quizá un 70 por 100 , si se admite que el diezmo está infravalorado cerca del 50 por 100. Pero con todas las ocultaciones que se quiera en el valor de las pensiones forales $y$, sobre todo, de los diezmos, no parece que las rentas provinciales representen, hacia 1755 sumadas a las "rentas feudales no centralizadas", menos del 20 por 100 maxime si se tiene en cuenta que a los 6,76 millones que iban a la Hacienda Real habría que añadirles las cantidades de alcabalas enajenadas, unos 550.617 rs. (un $7,5 \%$ del total de las rentas provinciales, bien que esos 550.617 rs. incluyen el valor de alcabalas y oficios enajenados. Si el cálculo se hiciese tan sólo sobre alcabalas y cientos resultan enajenadas, a mediados del siglo XVIII, un $14-15 \%$ del total) ${ }^{3}$.

1 AGS, DGR, 1. ${ }^{a}$ R, Leg. 2153. El valor de diezmos y foros de AHN, Hacienda, Legs. 7440,7441 y 7442 .

2 Sobre las ocultaciones del Catastro, J. M. Pérez Garcia: «Fuentes de control de los catastros fiscales: las escrituras de protocolos", en A. EIRAS ROEL et alii: Las Fuentes y los métodos, Santiago 1977, así como "Algunas reflexiones en torno a la utilización de los resúmenes generales de la Única", Cuadernos de Estudios Gallegos, XXXI (1982).

${ }^{3}$ Esta proporción es aproximativa; vale para un momento dado, y no para otros, pues en cada momento concreto habría que tener en cuenta el valor de las rentas de los contratos agrarios, el nivel de la producción agraria (condicionante de los diezmos) y de los precios agrarios, y la propia evolución de la fiscalidad real. Lo que queremos señalar, en todo caso, es que, por relación al resto de los fiscos, el de la Hacienda Real era, a mediados del siglo XVIII, más importante de lo que a primera vista podría pensarse. 
Las cantidades satisfechas al fisco real en concepto de rentas provinciales no eran, en cualquier caso, insignificantes. Empero, por comparación al resto de la corona de Castilla no puede decirse que Galicia estuviese sobrecargada: el reino gallego pagaba en 1755 un 7,2 por 100 del total de rentas provinciales con que contribuía el territorio de la corona castellana, cuando su población, según el Catastro de Ensenada, representaba el 19 por 100 y su producto bruto agricola y ganadero el 9,3 por 100. Habida cuenta del carácter fundamentalmente urbano de la fiscalidad real, Galicia, país ruralizado, de pequeños campesinos y rentistas, con una población urbana que en 1750 no era más del 5 por 100 del total, no contribuía en proporción menor al número de vecinos. Con todo, los porcentajes que Galicia aportó al fisco real variaron con el tiempo y también sufrió modificaciones la distribución de las diversas cargas en el interior del Reino. En las breves páginas que siguen nos proponemos hacer algunas consideraciones sobre los repartos, entre las diversas provincias gallegas, de las rentas provinciales; sobre la evolución del sistema fiscal (cantidades pagadas por Galicia, importancia porcentual con respecto a la corona de Castilla, reparto) y sobre la participación de los naturales (oligarquías urbanas, concejos abiertos) a la hora de determinar la forma de distribución y recaudación de las diversas cargas. Nuestras pretensiones no se dirigen a dilucidar los problemas teóricos que plantea el estudio de los diversos conceptos fiscales en el Antiguo Régimen ${ }^{4}$, sino, más modestamente, a poner de relieve la incidencia que en un país ruralizado como Galicia tiene una fiscalidad básicamente de tipo urbano; cómo se reparten y cobran las cargas y en qué medida las formas de reparto y cobranza de las rentas provinciales explican la ausencia o no de resistencias antifiscales.

\section{LA DISTRIBUCIÓN DE LAS RENTAS PROVINCIALES DENTRO DE GALICIA}

El sistema fiscal articulado en torno a las rentas provinciales habia adquirido sus trazos fundamentales desde fines del xvi, con el estable-

4 Sobre los problemas conceptuales que plantea la fiscalidad real y su concurrencia con otros fiscos, remitimos a los trabajos de B. Clavero: “Hispanus fiscus, persona ficta. Concepción del sujeto político en el ius commune moderno", en Tantas personas como Estados, Tecnos, 1986, y "Señorio y Hacienda a fines del Antiguo Régimen en Castilla. A propósito de recientes publicaciones", Moneda y Crédito, 135, 1975. También A. M. HESPANHA: As vèsperas do Leviathan, Lisboa 1987, pp. 163 ss. 
cimiento del servicio de millones y la fijación de reglas para su recaudación, y con la implantación de los cientos en el curso del $x V I^{5}$. Ello no quiere decir, sin embargo, que los repartos de unas y otras rentas fuesen absolutamente rígidos a lo largo del tiempo. Según cifras de 1780 , Galicia pagaba a la sazón 7,85 millones de rs. de rentas provinciales, correspondiendo un 48 por 100 a los millones y rentas anexas, otro tanto a las alcabalas, y un 4 por 100 al servicio ordinario y extraordinario. La distribución de la cantidad anterior entre las siete provincias era como sigue.

CUADRO I. REPARTO DE LAS RENTAS PROVINCIALES, EN 1780, EN MARAVEDÍS

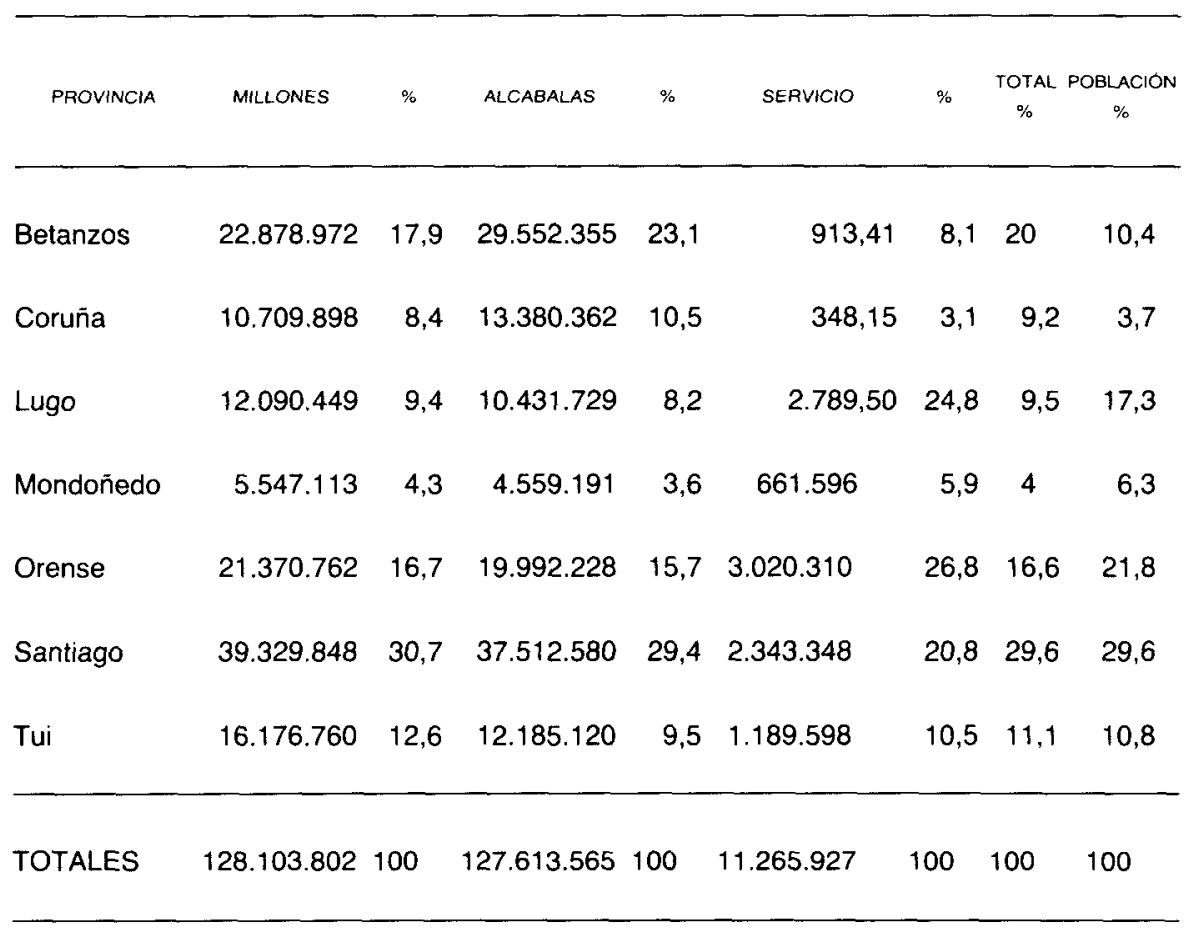

Fuente: AGS, DGR, 1. ${ }^{\mathrm{a}}$ R. Leg. 2159.

${ }^{5}$ Vid., con carácter general, M. ARTola: La Hacienda del Antiguo Régimen, Madrid 1982, pp. 91 ss. 
Tal como puede observarse, cada provincia contribuye con un porcentaje diferente en el caso de los millones, alcabalas y servicio ordinario y extraordinario. Si el reparto de alcabalas y millones es bastante parecido, el de los servicios difiere notablemente debido a que su distribución intraprovincial sigue a fines del XVIII arreglada al vecindario de 1591. Ahora bien, si el servicio mantiene una gran rigidez (que no parece provocar graves problemas, por el carácter cuasi residual que esta renta va adquiriendo desde la primera mitad del XVII), no sucede lo mismo con las otras rentas, y en particular con los millones, que demuestran una gran flexibilidad. Podemos verlo analizando repartos diversos, desde su misma implantación hasta los años finales del Antiguo Régimen:

CUADRO $\|$

PORCENTAJE DE CADA PROVINCIA EN VARIOS REPARTOS DE MILLONES

\begin{tabular}{lcccccc}
\hline \multicolumn{1}{c}{ PRovincia } & $1531-94$ & $1595-96$ & 1624 & 1678 & 1780 & 1827 \\
\hline Betanzos & 14 & 10,6 & 6,9 & 5,5 & 17,9 & 12,2 \\
Coruña & 26,6 & 25,5 & 13,9 & 13,1 & 9,4 & 9,1 \\
Lugo & 6,9 & 5,8 & 6,5 & 3,8 & 4,3 & 5,2 \\
Mondoñedo & 20,3 & 27,4 & 21,7 & 18,7 & 16,7 & 14,8 \\
Orense & 26 & 20,5 & 31,1 & 41,2 & 30,7 & 30,4 \\
Santiago & 6,2 & 10,2 & 15,2 & 12,8 & 12,6 & 18,1 \\
Tui & 100 & 100 & 100 & 100 & 100 & 100 \\
\hline
\end{tabular}

Fuente: elaboración propia a partir de: para 1591-96, M. ULLOA: La Hacienda Real de Castilla en el reinado de Felipe 11 , p. 524; para 1678, E. FERnÁnDEZ-VILLAMIL: Juntas del Reino de Galicia, II, p. 304; para 1624 y 1780, AGS, Contadurias Generales. Leg. 3369, y DGR, 1. ' R., Leg. 2159, respectivamente. Para 1827 , AHN, Hacienda, Leg. 1835. 
El primer reparto de millones se acomodó al número de vecinos que cada provincia tendría en el vecindario de 1528. El de 1595-96 se ajusta al vecindario de 1591, que, como es bien sabido, se llevó a efecto precisamente para la distribución de estos nuevos servicios ${ }^{6}$. En el censo de 1591, que parece ser muy desigual en Galicia, las provincias de Lugo y Orense aparecian, en términos absolutos, como los de mayor vecindario, lo cual es más que dudoso. En los repartos posteriores se procedió a diversos reajustes orientados principalmente a desgravar las provincias interiores a costa de cargar mayor porcentaje a Santiago y Tui. Esta tendencia se percibe ya en 1624, y sobre todo en 1678: Lugo y Orense pagan en $1595-96$ el 52,9 por 100 de los millones, y Santiago y Tui el 30,7 ; en 1624 los porcentajes son, respectivamente, de 35,6 y 46,3 y en 1678 de 31,8 y 54 . En esta evolución no ha de verse tan sólo el estancamiento del interior frente al despliegue del litoral -cosa que existe, pero afecta sobre todo al mundo rural, en donde se pagan pocos millones-, sino la corrección de repartos efectuados de manera poco ajustada al potencial urbano, reflejado en el consumo de determinados artículos, de cada provincia, pues los millones gravarán fundamentalmente el consumo urbano. Tal es la razón por la que Lugo, la provincia más ruralizada de Galicia, se va desgravando progresivamente, en tanto crece el porcentaje a pagar por otras provincias (primero por Santiago, $y$ desde fines del XVII por Betanzos y Coruna).

Aunque conocemos menos repartos de alcabalas entre las diversas provincias de Galicia, no cabe duda de que este impuesto también fue objeto de reajustes, según se desprende de la comparación de la evolución de encabezamientos de localidades concretas, o de cifras generales, como las de 1780 y 1827.

${ }^{6}$ Sobre los criterios seguidos para los dos primeros repartos de millones, A. CASTILLO: "Population et "richese" en Castille durant la seconde moitié du XVle. siècle", Annales, 1968. 
CUADRO III

REPARTO DE LAS ALCABALAS ENTRE LAS PROVINCIAS DE GALICIA

\begin{tabular}{lcc}
\hline Betanzos & 23,1 & 12,3 \\
Coruña & 10,5 & 11,8 \\
Lugo & 8,2 & 10,9 \\
Mondoñedo & 3,6 & 3,1 \\
Orense & 15,7 & 19,7 \\
Santiago & 29,4 & 35,6 \\
Tui & 9,5 & 6,6 \\
\hline
\end{tabular}

Fuente: AGS, DGR, 1. ${ }^{\text {a }}$, Leg. 2159 y AHN, Hacienda, Leg. 1835.

La evolución no es exactamente igual a la de los millones, sobre todo en el caso de Tui y también de Orense. Pero las divergencias pueden explicarse en parte porque alcabalas y millones no se distribuyen según criterio exactamente igual, aunque unos y otros graven sobre todo el vino vendido por menor, como en seguida veremos.

A grandes rasgos, el reparto de alcabalas y millones entre las diferentes provincias guarda más relación con la importancia de las diversas economías urbanas que con el número absoluto de vecinos. Así, volviendo al reparto de 1780, podemos precisar que Betanzos, con un 10,4 por 100 de la población de Galicia (en 1787), paga un 20,5 por 100 de alcabalas y millones; Coruña, con un 3,7 por 100 en la población, paga 
un 9,4 por 100; en Santiago y Tui ambas variables están muy equilibradas: con un 29,6 y un 10,8 por 100 bien de población, respectivamente, contribuyen con un 30 y un 11,1 por 100 de alcabalas y millones. Lugo, Mondoñedo y Orense se encuentran, por fin, muy desgravadas, en relación a sus efectivos demográficos: representando el 17,3, 6,3 y 21,8 por 100 del potencial poblacional, aportan, por el orden señalado, el 8,8, el 4 y el 16,2 por 100 , de las rentas aludidas.

Podríamos establecer otras comparaciones además de las que se basa en el potencial demográfico. En el cuadro siguiente se pone de relieve el porcentaje que a cada provincia correspondía en el producto bruto agricola y ganadero en 1752 , asi como en las ganancias procedentes del comercio por mayor y por menor y en las alcabalas y millones.

\section{CUADRO IV}

REPARTO DEL P.B.A., DE LAS GANANCIAS COMERCIALES Y DE ALCABALAS Y MILLONES ENTRE LAS PROVINCIAS

\begin{tabular}{lccc}
\hline \multicolumn{1}{c}{ PROVINCIA } & PRODUCTO B.A. & $\begin{array}{c}\text { ACTIVIDAD } \\
\text { MERCANTIL }\end{array}$ & $\begin{array}{c}\text { ALCABALAS Y } \\
\text { MILLONES (1780) }\end{array}$ \\
\hline Betanzos & 9,9 & 7,6 & 20,5 \\
Coruña & 4,2 & 29,7 & 9,4 \\
Lugo & 14,8 & 4,7 & 8,8 \\
Mondoñedo & 6,7 & 3,9 & 4 \\
Orense & 26,7 & 13,4 & 16,2 \\
Santiago & 29,3 & 33,8 & 30 \\
Tui & 8,7 & 6,9 & 11,1 \\
\cline { 2 - 4 } & 100 & 100 & 100 \\
\cline { 2 - 4 } & & &
\end{tabular}

Fuente: AHN, Hacienda, Leg. 7442. 
La carga fiscal no parece estar en relación ni con el potencial agrícola de cada provincia ni con la importancia porcentual de las actividades mercantiles, salvo en el caso de Santiago, en donde las tres variables se equilibran. En el resto de los casos se producen situaciones diferentes: la de las provincias más "ruralizadas", que pagan menos de lo que les correspondería por su actividad agrícola, pero más de lo que representan sus actividades mercantiles (caso sobre todo de Lugo, y también de Orense y Mondoñedo); la de Coruña, inversa a la anterior?, y la de Tui y sobre todo Betanzos que contribuyen en porcentajes superiores a las que les correspondería por unas y otras actividades (en el caso de Betanzos ello se explica en buena medida por el papel de Ferrol como centro de consumo).

Si se desmenuzan los repartos de alcabalas y millones de cada provincia se evidencia su carácter de fiscalidad urbana, que grava sobre todo la venta y consumo de vino. Uno de los casos más ilustrativos es el de Ferrol, población que en 1780 pagaba junto con los fielatos de la Graña y Mugardos, el 70 por 100 de los millones correspondientes a la provincia de Betanzos, repartidos entre los siguientes ramos:

' Ha de tenerse en cuenta, con todo, que entre 1752 y 1780 creció la importancia comercial de la provincia coruñesa. Vid. L. ALONso: Comercio colonial y crisis del Antiguo Régimen en Galicia (1778-1818), Coruña 1986. 
CUADRO V. DISTRIBUCIÓN DE LOS MILLONES DE LA CIUDAD DE FERROL

\begin{tabular}{|c|c|c|}
\hline RAMOS & MARAVEDIS & $\%$ \\
\hline Vino por menor $\ldots \ldots \ldots \ldots \ldots$ & 9.135 .264 & 66,1 \\
\hline Vino por mayor ............... & 527.120 & 3,8 \\
\hline Ramo volante $\ldots \ldots \ldots \ldots \ldots \ldots$ & 1.531 .071 & 11,1 \\
\hline Carnes $\ldots \ldots \ldots \ldots \ldots \ldots \ldots \ldots$ & 2.630 .366 & 19 \\
\hline TOTAL $\ldots \ldots \ldots \ldots \ldots \ldots$ & 13.823 .821 & 100 \\
\hline Tabernas ... & 14.790 & \\
\hline Filete de La Graña ............. & 1.255 .107 & \\
\hline Fielato de Mugardos & 267.156 & \\
\hline TOTAL & 1.537 .053 & \\
\hline
\end{tabular}

Fuentes: AGS, DGR, 1. ${ }^{\mathrm{a}}$ R. leg., 2159.

De las alcabalas de la provincia, la administración de Ferrol incluidos los fielatos de Graña y Mugardos, como en el caso anterior, paga el 80,8 por 100, distribuida la cantidad total entre los siguientes ramos: 
Estudio de las rentas provinciales de la Galicia del Antiguo Régimen

CUADRO VI. DISTRIBUCIÓN DE LA ALCABALA DE LA ADMINISTRACIÓN DE FERROL, 1780

\begin{tabular}{|c|c|c|}
\hline RAMOS & MARAVEDIS & $\%$ \\
\hline Vino por menor .... & 6.090 .176 & 27 \\
\hline Vino por mayor .... & 64.294 & 0,3 \\
\hline Carnes $\ldots \ldots \ldots \ldots \ldots$ & 1.753 .576 & 7,8 \\
\hline Géneros ultramarinos $\ldots \ldots \ldots \ldots$ & 1.020 .713 & 4,5 \\
\hline Tiendas y oficios $\ldots \ldots \ldots \ldots \ldots$ & 1.363 .170 & 6 \\
\hline Ventas a la marina $\ldots \ldots \ldots \ldots \ldots$ & 603.990 & 2,7 \\
\hline Tejidos de lana extranjeros ....... & 2.323 .284 & 10,3 \\
\hline Tejidos de lana del reino....... & 2.650 .912 & 11,8 \\
\hline Géneros entregados al arsenal ... & 6.061 .123 & 26,9 \\
\hline Raíces ........... & 612.894 & 2,7 \\
\hline TOTAL .......... & 22.544 .132 & 100 \\
\hline Tabernas de las feligresías ....... & 9.860 & \\
\hline Fielato de Graña & 1.014 .899 & \\
\hline Fielato de Mugardos ... & 316.624 & \\
\hline TOTAL & 1.341 .383 & \\
\hline
\end{tabular}

Fuente: AGS, DGR, 1. ${ }^{\mathrm{a}}$ R. Leg. 2159. 
Nos parece que el caso de Ferrol demuestra palpablemente el carácter urbano de las alcabalas y millones, la flexibilidad de estas rentas (que gravan en este caso una economía urbana de expansión reciente), y lo que es ya bien conocido, el papel del "sector público" - expresión sin duda impropia-, tiene en la vida económica de Ferrol. Pero pueden aducirse otros muchos ejemplos que demuestran que la fiscalidad recae principalmente en los núcleos urbanos, y que es la venta y consumo de vino por menor el ramo que aporta un porcentaje substancial, más elevado, por su propia naturaleza, en el caso de los millones. La ciudad de Santiago pagaba en 1780 un 28 por 100 aproximado de los millones de la provincia, repartidos entre los siguientes "miembros":

\section{CUADRO VII. DISTRIBUCIÓN DE LOS MILLONES DE LA ADMINISTRACIÓN DE SANTIAGO}

\begin{tabular}{|c|c|c|}
\hline RAMO & MARAVEDIS & $\%$ \\
\hline Vino por menor & 7.277 .783 & 84,2 \\
\hline Vino por mayor ..... & 728.605 & 8,4 \\
\hline Aceite $\ldots \ldots \ldots$ & 272.000 & 3,2 \\
\hline Tratos y gremios (encabezados) & 364.476 & 4,2 \\
\hline TOTAL & 8.642 .864 & 100 \\
\hline Tabernas de las provincias ....... & 221.974 & \\
\hline Partidos y lugares encabezados & $13.301 .222^{1}$ & \\
\hline Fiel medidor .. & 1.701 .550 & \\
\hline
\end{tabular}

' En la administración de la ciudad.

Fuente: AGS, DGR, 1. ${ }^{a}$ R. Leg. 2159. 
Estudio de las rentas provinciales de la Galicia del Antiguo Régimen

La alcabala en esta ciudad es recaudada sobre el vino ante todo, y sobre ferias y diversos géneros vendidos, siendo muy escasa la cantidad aportada por los gremios artesanales:

\section{CUADRO VIII. REPARTO DE LAS ALCABALAS DE SANTIAGO, EN 1780}

\begin{tabular}{|c|c|c|c|c|c|}
\hline RAMO & MARAVEDIS & $\%$ & RAMO & MARAVEDIS & $\%$ \\
\hline Vino $\ldots . . . \ldots$ & 4.078 .249 & 36,9 & Merc. de ganados $\ldots . . .$. & 325.316 & 3 \\
\hline Pescadería .... & 479.124 & 4,3 & Merc. de S. Lorenzo ....... & 5.100 & 0,1 \\
\hline Ferias $\ldots \ldots \ldots$ & 623.628 & 5,6 & & & \\
\hline Puertas ...... & 882.378 & 8 & Alhóndigas ... & 378.080 & 3,4 \\
\hline Madera ....... & 38.626 & 0,4 & Tratos y gremios & 1.022 .362 & 9,3 \\
\hline Raices ........ & 26.452 & 0,2 & Joyerías paños, seda.... & 1.305 .362 & 11,8 \\
\hline \multirow[t]{4}{*}{ Nieve } & 14.343 & 0,1 & & & \\
\hline & & & Tejidos de lana del Reino & 720.826 & 6,5 \\
\hline & & & Id. Extranjeros & 1.107 .734 & 10 \\
\hline & & & Herrajes y clavazón .. & 42.636 & 0,4 \\
\hline
\end{tabular}

TOTAL

Tabernas en la provincia: $148.116^{\prime}$

Ferias de la provincia: $827.102^{1}$

Pueblos encabezados $16.995 .797^{1}$

' Que andan en la administración de la ciudad.

Fuente: AGS, DGR, 1. ${ }^{\text {a }}$ R. Leg. 2159. 
Igual sucedía en Pontevedra, en donde un 39 por 100 de las alcabalas se recaudaba sobre el vino, o en Noia en donde este porcentaje era del 40 por 100 . El encabezamiento de Pontevedra, que habia superado al de Santiago en la segunda mitad del XVI, era en 1780 unas siete veces inferior. El encabezamiento de la ciudad coruñesa era en esta fecha comparable al de Santiago, así en alcabalas como en millones; la ciudad herculina en la que vivía un 27 por 100 de los efectivos demográficos de la provincia, pagaba más del 80 por 100 de los millones y el 84 por 100 de las alcabalas ${ }^{8}$. Lugo, ciudad de ritmo candencioso y agrario, aparece más desgravada: si Coruña la supera 3, 4 veces en población, paga 7,2 veces más millones.

\section{EVOLUCIÓN DE LAS RENTAS PROVINCIALES}

Tal como dejamos indicado, a mediados del siglo xvIII el sistema fiscal mostraba unos trazos estructurales que había ido adquiriendo en el curso de los siglos anteriores. La situación fiscal de Galicia dentro de la corona de Castilla podemos resumirla diciendo que evoluciona, en el curso del XVI y parte del XVII, hacia una relativa desgravación -e insistimos en lo de relativa-, y en el XVIII se produce una situación inversa, cuando el reino gallego hará frente a un porcentaje de las alcabalas y millones cada vez más elevado, lo que refleja - aunque con tardanzala acomodación de la fiscalidad real al mayor dinamismo económico de la periferia.

El aumento del valor de las alcabalas que se registra sobre todo a partir de 1480 es un reflejo tanto de la afirmación del poder real como de la expansión de las economías urbanas, y por tanto de las transacciones. Con un índice 100 en 1450 , el valor de las alcabalas habría descendido a 69,6 en 1469; se situaría en 89 en 1482, en 190 en 1493 y en 210 en 1504. En ninguna otra parte de la corona de Castilla hay un

${ }^{8}$ La población de las villas y ciudades de Galicia, en 1787, en A. EIRAS RoEL: “Una primera aproximación a la estructura demográfica urbana de Galicia en el censo de 1787", en R. VILLARES (coordinador): La ciudad y el mundo urbano en la historia de Galicia, Universidad de Santiago, 1988, pp. 155 ss. 
crecimiento tan fuerte ${ }^{9}$. En cifras absolutas, el valor en arriendo de las alcabalas de Galicia es de 16,3 millones de maravedís en 1504 cantidad ésta que representa un 5,5 por 100 de todas las alcabalas de la corona de Castilla. El análisis por lo menor de los arriendos revela lo apreciadas que son las alcabalas urbanas; las de Lugo, en 1507, cuando la ciudad no debía pasar de ser un villorrio, valen en las subastas el 8,8 por 100 del total de las de la provincia, y las de la ciudad de Orense el 17,7 por $100^{10} \mathrm{si}$ bien es significativo que en los primeros encabezamientos que conocemos estos porcentajes desciendan (evidencia de la desgravación de las ciudades cabeza de provincia).

Los encabezamientos, extendidos a la generalidad de las poblaciones de la corona de Castilla en 1534-36 (aunque, en ocasiones, existian ya desde la década de 1490 , y su mantenimiento había sido un problema no secundario en la guerra de las Comunidades), supusieron ventajas considerables sobre todo para las ciudades. Algunas cifras son bien ilustrativas: las alcabalas de la ciudad de Lugo valían en arriendo, en $1.507,200.236$ mvs.; en 1540, en cambio, el encabezamiento era de 104.000 mvs., en 1561, de 121.000; en 1579-88 de 239.000, y en 159097 de 242.585 mvs. El arriendo de 1507 duplica por tanto, el valor del encabezamiento de 1540, y es sólo un 21 por 100 inferior al encabezamiento 1590-97. Por lo que toca a Orense, de un arriendo que asciende a $611.000 \mathrm{mvs}$. en 1503 se pasa a un encabezamiento de 361.000 en 1544 , y de 474.500 en 1547-56; hay que llegar a 1565 , con un encabezamiento de 750.000 mvs., para superar la cifra de 1503; en 1590-97 se le reparten a la ciudad 1.114 .876 mvs., cantidad un 82,5 por 100 superior a la del arriendo de $1503^{11}$. Algunas cifras globales - para toda Galicia- de que se dispone indican también un crecimiento moderado de la alcabala si se toma en consideración todo el siglo XVI: si en 1504 ascendian a 16,3 millones de maravedis, un resumen de 1603 les otorga un valor de 29,8 millones (un 83 por 100 más); de acuerdo con esto Galicia pagaba en la primera fecha el 5,5 por 100 del total de la corona de Castilla, y en la segunda un 2,8 por 100 (el porcentaje, de hacer entrar en el cómputo las alcabalas enajenadas, seria aún inferior, porque en Galicia pocas lo estaban) ${ }^{12}$.

9 Vid. M. A. Ladero Quesada: La Hacienda Real de Castilla en el siglo XV, La Laguna 1973 , p. 86.

${ }_{10}$ AGS, EdH, Legs. 118-8-1 (Lugo) y 135-5 (Orense).

"AGS, EdH, Legs. 118-8-1 y 97 (Lugo), y 135-5,95 y 96 (Orense).

${ }_{12}$ M. ARtola: La Hacienda, pp. 73 y 143 (en este último caso con un error de imprenta que no afecta al porcentaje). 
En la segunda mitad del XVI las alcabalas se consolidan como impuesto fundamentalmente urbano, incidiendo sobre todo en las villas del litoral atlántico, más florecientes. Bastará señalar al respecto que Noia, por ejemplo, con unos 550 vecinos en 1557, pagaba más alcabalas que toda la provincia de Mondoñedo, cuya población sería diez veces superior, o que la cantidad cargada a Pontevedra equivalía a dos tercios del encabezamiento de la provincia de Lugo, con una población quince veces superior. En la década de 1590 la villa pontevedresa tenia un número de vecinos 3,5-4 veces superior a la ciudad de Lugo, pero su encabezamiento le multiplicaba por $10^{13}$. Estas desigualdades aconsejan cierta prudencia a la hora de valorar la incidencia del fisco real atendiendo tan sólo a cifras medias, sin tomar en consideración el muy desigual reparto de los impuestos.

Con todo, incluso aquellos núcleos urbanos más sobrecargados (como Pontevedra), hacen frente a los encabezamientos sin grandes agobios hasta fines del XVI. El encabezamiento de Pontevedra se multiplica por 2,25 entre 1557-61 y 1550-97, pero la persona que se queda con el arriendo que efectúa el concejo en 1593 promete algunas rebajas en determinados porcentajes a percibir sobre las transacciones y ofrece 800 ducados para diversos gastos de la villa (pleitos, cofradias...); salvo del pescado, del que se pagaba el 9 por 100 , del resto de las ventas se pagaban porcentajes bajos, del orden del 2-4 por 100. También en Orense hay una situación de cierto desahogo, pues las "sobras" - cantidad efectivamente recaudada por encima del valor del encabezamiento-fueron en 1590 del 22 por 100 y en 1595 del 33 por $100^{14}$.

El reparto de las alcabalas entre los diversos miembros urbanos pone de relieve la escasa "base industrial» de las ciudades y villas gallegas, que han de recaudar una parte sustancial del impuesto gravando el tráfico de vino, la venta de paños y la buhonería. De entre los gremios sólo el de zapateros parece tener algún relieve, y en el litoral el de pescadores (que puede encabezar, conjuntamente, la alcabala del alfoli, diezma y pescado). A continuación se muestran los porcentajes que corresponden, de la alcabala, a cada miembro en Lugo y Pontevedra, en diversos repartos:

13 AGS, EdH, Legs. 97 (Noia) y 144 (Pontevedra).

${ }^{14}$ AGS, EdH, Legs. 144. 
Estudio de las rentas provinciales de la Galicia del Antiguo Régimen

CUADRO IX. REPARTO DE LA ALCABALA EN LA CIUDAD DE LUGO, EN PORCENTAJE

Paños

11,2

8,1

7,1

Vino

14,6

38,7

31,2

Pescado

6,6

3,4

5,8

Carnicería

11,4

9,4

4

Zapatería

25,4

10,4

14,3

Peleteria

1,6

Foránea

11,2

18,8

17,8

Buhonería

1,8

2,8

3,6

Heredades

1,8

Merceria

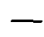

5,2

6,3

Aceite

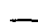

3,2

2,2

Sebo y menudencias
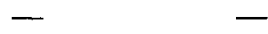

7,7

Otros

2,5 


\section{REPARTO DE LA ALCABALA EN LA CIUDAD DE PONTEVEDRA, EN} PORCENTAJE

\begin{tabular}{|c|c|c|c|}
\hline MIEMBRO & 1557 & $1579-83$ & 1584 \\
\hline Pescado, alfolí y media diezma .. & 40 & 40,9 & 47,5 \\
\hline Vino $\ldots \ldots \ldots \ldots \ldots \ldots \ldots \ldots$ & 23,6 & 24,6 & 20 \\
\hline Paños $\ldots \ldots \ldots \ldots \ldots \ldots \ldots \ldots$ & 3,3 & 2,5 & 3,8 \\
\hline Fierro $\ldots \ldots \ldots \ldots \ldots \ldots \ldots \ldots$ & 1,9 & 1,7 & 1,8 \\
\hline Cueros y zapatería .............. & 2,8 & 4,3 & 2,1 \\
\hline Madera $\ldots \ldots \ldots \ldots \ldots \ldots \ldots$ & 5 & 6,9 & 6,6 \\
\hline Salvajina $\ldots .$. & 6,5 & 8,9 & 10,8 \\
\hline Carnicería & 4,8 & 2,7 & 2,3 \\
\hline Bestias y negros & 0,3 & 0,2 & 0,3 \\
\hline Plaza y pan...$\ldots \ldots$ & 10,6 & 5,5 & 4,1 \\
\hline Aumentos $\ldots \ldots \ldots \ldots \ldots \ldots \ldots$ & 1,5 & - & - \\
\hline Cestería & - & 0,9 & 0,7 \\
\hline \multirow[t]{2}{*}{ Otros } & - & 0,9 & - \\
\hline & 100 & 100 & 100 \\
\hline
\end{tabular}

Fuente: AGS, EDH, Legs. 97 y 118 (Lugo) y 144 (Pontevedra).

En el caso de Lugo, las cifras de 1507 son resultado del valor que alcanza cada miembro en arriendo; las cifras de 1579 combinan arriendo y reparto y las de 1594 corresponden a repartos tan sólo. La evolución 
del peso porcentual de cada ramo denota que la ciudad tiende a convertirse en un centro consumidor y redistribuidor de mercancías, antes que en un centro artesanal. Tal es lo que parece colegirse de la importancia del miembro del vino en la segunda mitad del xvi, en tanto pierde peso la zapatería. En Pontevedra, cualquiera que sea el sistema de cobro -repartos y arriendos en 1557; mediante fieldad en 1579-83, arriendo en 1584- pescado, alfolí (antes del estanco de la sal) y media diezma, por un lado, suponen en torno a dos tercios del total del encabezamiento. Fuera de los pescadores, sólo los trabajadores de la madera (toneleros) tienen una mínima relevancia. La villa pontevedresa vive, por tanto, de la pesca y de la exportación de vino de la provincia de Orense (el vino de la Ulla exportado no llega en 1584 a ser un 10 por 100 del total); 111 mercaderes de vino cotizan en 1557, si bien uno solo paga el 11,5 por 100 del total. Los datos de otras poblaciones confirman lo que venimos indicando: en Noia el vino aporta en 1557, el 36 por 100 del encabezamiento y la pesca y alfolí el 43,2 por 100 , sin que ningún gremio de artesanos llegue a cargar con el 3 por 100; en Coruña la diezma, pescado y alfoli representan el 44,4 por 100 en 1542-46, y el vino el 18,1 por 100 en 1581-82, sin embargo, el vino supone ya el 32,4 por 100 , lo que parece demostrar que la ciudad tiende a ser cada vez más centro de consumo (en razón de la burocracia y milicia que se va asentando en ella) ${ }^{15}$.

Por lo que respecta al mundo rural, conocemos numerosísimos repartos de alcabalas de mediados del siglo xvi (y luego para el xVII) que se conservan en el AGS, en los protocolos y en fondos municipales. No nos extenderemos ahora sobre el hecho de que, en el mundo rural, la alcabala suele ser un impuesto directo; cabe mencionar tan sólo que la cuota media es muy desigual de unos "partidos" a otros, y que las mayores cuotas parecen alcanzarse en los pequeños cotos (en el orensano de San Cibrao de Viñas, por ejemplo, se pagan $464 \mathrm{mvs}$. de media en 1557-61, en tanto que en la extensa jurisdicción de Viana sólo 55). La evolución de los encabezamientos en el mundo rural en la segunda mitad del XVI presenta también notables desigualdades: si en diversos partidos de Mondoñedo aumentaron un 64 por 100, y en la tierra de Santiago un 80-90 por 100, en Caurel el porcentaje fue de 38 y en Viana

15 AGS, Legs. 97 (Noia) y 86 (Coruña). Tanto en estos casos como en los citados antes sería preciso afinar más los análisis, porque la alcabala no gravaba por igual todos los productos, como se vio a propósito de Pontevedra. Con todo, los porcentajes son indicativos. Para comparar con otros repartos por menor, vid., M. UlloA: La Hacienda Real de Castilla en el reinado de Felipe II, Madrid 1977, pp. 174 y ss. 
del 305 (jurisdicción muy descargada como vimos, en 1557-61). Aumentaron también, por regla general, los contribuyentes, de manera que al filo de 1590 las cuotas medias se sitúan en torno a 110-180 mrs., cantidades muy inferiores, desde luego, a los que correspondian al mundo urbano: ca. $1500 \mathrm{~ms}$./vecino en Pontevedra, ca. 1300 en Santiago, ca. 1200 en Orense, ca. 550 en Lugo y ca. 425 en Mondoñedo ${ }^{16}$.

A primera vista puede parecer sorprendente que en los partidos rurales las cuotas del servicio ordinario y extraordinario -renta a la que buena parte de la historiografía no suele prestar demasiada atenciónsuperen a las de las alcabalas. Ha de recordarse al respecto que Galicia pagaba, en la segunda mitad del XVI, después de reajustes en 1540-42, el 7-8 por 100 del servicio - porcentaje que duplica al menos al que le corresponde por alcabalas - y que en determinados momentos el servicio sufrió añadidos, por mor de reales casamientos sobre todo, de manera que podía equivaler a una tercera parte o a la mitad de las alcabalas; además, y muy importante, a diferencia de alcabalas y luego de los millones, el servicio ordinario y extraordinario pesa básicamente sobre el campesinado, y no lo paga la hidalguía ni, a menudo, las viudas. La restricción del número de cotizantes y su carácter rural - -hay ciudades que lo pagan con un juro- explican que en la provincia de Mondonedo en el tránsito del XVI al XVII sea posible hallar cuotas medias de 250-270 mvs, por sujeto fiscal ${ }^{17}$. Otro indicio más de que el peso de la

${ }^{16}$ Las cifras se han obtenido a partir de los datos del AGS, EdH, legajos ya citados, y por medio de la consulta del Arch. de Protocolo de Mondoñedo. Los de Santiago, en J. E. Gelabert: Santiago y la Tierra de Santiago de 1500 a 1640, Coruña-Sada 1982, pp. 124 y ss. Las contribuciones medias de alcabala en el mundo rural son muy inferiores a las de los pueblos de Córdoba, como puede verse por los datos abundantes y precisos de J. I. Fortea PÉrEz: Fiscalidad en Córdoba, Córdoba 1986, apéndice II, pp. 157 y ss. (cuotas por vecino en $1590-95$ que van de 273,7 a 1767,8 mvs). Hemos de advertir con todo, que en Galicia podia en ocasiones haber más cuotas que vecinos, y que la alcabala "del viento" o "foránea", cuando existía, oscilaba entre el 5-15 por 100 del encabezamiento. Sobre la cuestión de "vecinos y cotizantes" remitimos a nuestro trabajo "Algunos problemas que plantean las fuentes fiscales del Archivo General de Simancas", en Jubilatio: Homenaje de la Facultad de Geografia e Historia a los profesores D. Manuel Lucas Alvarez y D. Ángel Rodriguez González Univ. de Santiago, 1987, pp. 344 y ss., y a la monografía Economia, politica y sociedad en Galicia: la provincia de Mondoñedo, 1480-1830, Madrid 1985, pp. 497 y ss.

17 Hasta los reajustes de 1540-42 Galicia paga del 11 al 12 por 100 del servicio; su porcentaje descendió entonces al 8,26 por 100 y en la década de 1640 era del 6,3 por 100. Vid, J. M. Carretero Zamora: Cortes, Monarquia, Ciudades. Las Cortes de Castilla a comienzos de la época moderna, Madrid 1988, pp. 94-95, y A. Dominguez Ortiz: Política y Hacienda de Felipe IV, Madrid 1960, pp. 370-371. Repartos de la segunda mitad del XVI en M. UlLoA: La Hacienda Real..., op. cit., pp. 482-484. Las formas de reparto y las cuotas del 
fiscalidad real ha de estudiarse atendiendo a las características especiales de cada renta, sin que sea suficiente acudir a cifras medias que ocultan matices importantes.

Con el establecimiento del servicio de millones y la fijación de las formas de percepción el sistema fiscal adquirirá unas características que, en sus trazos fundamentales, se mantendrán hasta bien entrado el siglo XIX. En el primer reparto de este servicio (1591-94) a Galicia le correspondieron 32,4 millones de maravedís anuales, cantidad que equivalía al 6,5 por 100 de lo repartido a la corona de Castilla; en el segundo reparto (1595-96) este porcentaje descendió al 4,9 por 100. Esta desgravación relativa continuará en la primera mitad del XVII, conforme los millones se recauden, sustancialmente, sobre el consumo urbano (en 1662 el porcentaje era del $1,3 \%)^{18}$. Al percibirse por medio de una sisa, su implantación en las aldeas era más que dificil, de los que hay elocuentes testimonios. El mismo factor que provocó reajustes en la distribución en el interior de la corona de Castilla los causó igualmente dentro de Galicia. Atrás quedaron indicados los porcentajes que en sucesivos repartos correspondieron a la provincia, como los repartimientos de 1591-94 y 159596 se acomodaban, respectivamente, a los censos de 1528 y 1591, y como había nuevas modificaciones en el curso del XVII ( $y$ luego en el XVIII $y$ primer tercio del $x(x)$.

En el primer reparto de millones quedó a voluntad de los partidos arbitrar los medios para la recaudación. Las soluciones fueron diversas: en Lugo se hizo un repartimiento directo tan sólo entre los mercaderes de vino; en Viveiro otro, pero entre todos los legos, incluidos los hidalgos; en alguna feligresía dependiente de la villa anterior los vecinos impusieron un canon a los ganados que venian a pastar a sus términos... A partir de 1601, y pese a su carácter de servicios, los millones se consolidan como impuestos indirectos, recaudados mediante una sisa sobre el

Servicio de algunos partidos en P. Saavedra: Economia, Política..., op. cit., pp. 503 y ss., y 601-602. Los diversos estudiosos de la Hacienda Real del s. XVI no dejan de insistir en que durante el reinado de Carlos $\mathrm{V}$ las cortes renovaron y aumentaron las cantidades del servicio, a cambio de la congelación de las alcabalas, y si bien los millones eran un servicio sin exentos, acabaron recaudándose como sisas. La diferencia entre el servicio ordinario y extraordinario de un lado, y el servicio de millones de otro, no precisa mayores comentarios.

${ }_{18}^{18}$ Los repartos en M. ULLOA: La Hacienda Real..., op. cit., p. 524, y M. ARTOLA: La Hacienda, p. 127. 
vino y luego también sobre el aceite, el vinagre y la carne ${ }^{19}$. Por lo que ya vimos, el vino aportó más del 70 por 100 del total y en el mundo rural a veces el 100 por 100 . El carácter de los millones como puesto urbano aparece claramente en la primera mitad del XVII: en 1624 la ciudad de Betanzos, en la que en 1591 vivian el 6 por 100 de los vecinos de la provincia, pagaba el 21,2 por 100 de lo que correspondía a ésta; en 1630 Santiago y Pontevedra vienen a pagar un 50 por 100 de los millones de toda la provincia, cuando su vecindario representaría el 6,5 por 100. Este proceso se acentúa: en 1640 el porcentaje que le corresponde a la ciudad de Betanzos es del 33 por 100, y a la de Lugo del 24,6 por 100 (en 1610 el 10 por 100). Por su carácter de sisa sobre ciertos artículos, los millones se revelarán como impuestos de gran flexibilidad, y su distribución puede servir de índice para ver el mayor o menor consumo urbano. Es ilustrativo, al respecto, la comparación Santiago-Pontevedra: en 157984 el encabezamiento de alcabalas de esta población superaba al de Santiago en un 42 por 100 , y en 1640 en un 15 por 100 , en los millones de 1630 , en cambio, Santiago aventaja a Pontevedra en un 13 por 100 , $y$ en 1640 en un 41 por $100^{20}$. La administración mediante fieles y el hecho de que cada ciudad, por turno, fuese arquera o tesorera de los millones permitían conocer el mayor o menor consumo urbano, y efectuar los oportunos reajustes. La contabilidad que de la primera mitad del XVII se conserva en el AGS asombra por su detallismo y es susceptible de ser aprovechada para conocer aspectos importantes de las economías urbanas.

Estos reajustes continuos están detrás de varias disensiones que a mediados del XVII surgieron entre las ciudades cabeza de provincia, representadas en las Juntas del Reino. En la Junta de 1646 los procuradores se ofrecieron a tomar las sisas en encabezamientos, so color de

${ }^{19}$ Reiteramos lo señalado en la nota 17: los millones son servicios, pero sin exentos, y acaban reducidos a sisas. En el reparto directo que conocemos de 1592, de la villa de Viveiro, figuran 446 personas, que cotizan de 17 a 1870 mvs., cuota ésta que alcanza algún regidor; en el mundo rural hay cuotas de 17 a 1632 mvs. que satisfacen determinados hidalgos. Arch. Municipal de Viveiro, Arbitrios, Leg. 75. El cambio que significa la implantación de las sisas lo resumia en 1595 un procurador sevillano: Si se han cobrado sisas sin ruido "es porque no ha tocado a los ricos, que son los que tienen lengua, los que hablan y son oidos en las repúblicas y la suavidad que le hallan es que es sangre de los pobres y como éstos tienen tan pocos que vuelvan por ellos en la república, hacen de su agravio suavidad, de su injusticia, justificación", en Ch. JAGO: “Crisis sociales y oposición política: Cortes y monarquia durante el Reinado de Felipe II", Comunicación al Congreso de Historia de las Cortes de Castilla y León, Salamanca 1987, en prensa.

${ }^{20}$ A.G.S., Contadurias, Legs. 3769,3375 y 3393 , con toda clase de detailes sobre el consumo de los articulos sisados. 
evitar los «jueces, merinos y oficiales que crian los administradores de millones, con que los naturales del Reino se ven gravados de vejaciones y gastos, y con desaliento para la cultivación de las viñas". Aunque el encabezamiento se obtiene en 1657 y 1669, las provincias de Santiago y Tui se mostrarán disconformes con la forma del reparto: preferian el sistema rígido de tercias y sextas, seguido en los pedidos votados por las Juntas y luego en nuevos impuestos del XVIII, como los utensilios. Según este sistema, la provincia de Santiago corría con un tercio, Lugo y Orense con otro, y las cuatro provincias restantes, mucho más pequeñas, con el otro. Lugo y Orense, sobre todo, preferían un sistema de reparto que atendiese al consumo urbano de los artículos sometidos a la sisa; en función de este criterio habian venido desgravándose progresivamente desde los primeros repartos. Triunfó esta postura, siendo condenados en los testarudos procuradores de Santiago y Tui a "perpetuo silencio", por cédula de 4 de junio de $1678^{21}$. En esta fecha Santiago pagaba el 41,2 por 100 de los millones y Tui el 12,8 , cuando por el sistema de tercias y sextas habrian pagado, por el mismo orden, el 33,3 por 100 y el 8,3 ; Lugo y Orense pagaban el 31,8 , porcentaje que se reducirá en años posteriores (sobre todo en el caso de Lugo, como quedó indicado).

No es en absoluto fácil hacer una evaluación de la incidencia de la presión fiscal en diferentes momentos, sobre todo a partir de las cantidades globales de los diversos impuestos. Ya reiteramos que las rentas provinciales, y en concreto las alcabalas y millones, gravan ante todo los núcleos urbanos, y mucho menos el mundo rural. El camino menos impreciso para conocer la incidencia del fisco en el mundo rural sería acudir a los repartos nominales que de alcabalas, servicio ordinario y extraordinario, y al principio también de los millones se efectúan en cada partido, entre los varios sujetos fiscales. A tenor de esto ya avanzamos que en la década de 1590 las cuotas medias de alcabalas se sitúan en 110-180 mvs.; las de los primeros millones fueron en el corregimiento de Viveiro de 243 mvs., y de 210-245 mvs. otras parroquias mindonienses en la década de 1640 (momento en que las alcabalas oscilan, según los partidos, de 144 a 337 mvs./cotizante). Las cuotas del servicio fluctúan entre 1598 y 1615 de 220 a 270 mvs. por cotizante. Las comparaciones no son por completo homogéneas porque el servicio, según vimos, se reparte entre menos cotizantes. Parece, en todo caso, que los primeros

${ }^{21}$ Sobre los encabezamientos, Arch. Municipal de Coruña, Juntas del Reino, 1646, y E. Fernández Villamil: Juntas del Reino de Galicia, op. cit., II, pp. 278 y ss. 
millones suponen en el mundo rural un incremento de un 30-40 por 100 de la carga fiscal. En cifras globales, las rentas provinciales se multiplicaron por 3,5-4 entre la década de 1590 y la de 1660, fruto de la votación y renovación de los millones y del establecimiento de los cientos. A la altura de 1678 las diversas sisas y fiel medidor superaban en un 6 por 100 a las alcabalas y cientos $(82,5$ millones frente a 77,6$)$. No puede olvidarse, por otro lado, que en el segundo tercio del XVII existen continuos pedidos extraordinarios de los que dan amplia información las actas de la Junta del Reino y las actas municipales, y, además, está el problema del estanco de la sal; los valores brutos de la venta de sal desde 1574 superan a los del encabezamiento de alcabalas ( $y$ en el año mencionado se considera beneficio el $57 \%$ del producto de las ventas). La sal, que venía vendiéndose a 1-2 reales hasta 1564 , pasa entonces a 4; sube 2 reales en 1608 y llegaba a 16 rs. en 1669, año en que ascendió a 22. Descendería a 11 en 1691 para volver a 17 en 1693. Las dificultades y crisis profunda que los principales puertos pesqueros atraviesan desde mediados del siglo XVII tiene, tal vez, tanto que ver con la cuestión de sal como con el aumento de las rentas provinciales. Otra razón más para establecer matices a la hora de estudiar la incidencia de la Hacienda Real en la economía ${ }^{22}$.

Las exigencias fiscales no parecen haber generado, con todo, graves oposiciones, comparables al menos en tenacidad a las suscitadas en algunos concejos por las cargas señoriales. Desde luego que hay numerosas quejas, alguna de las cuales se acumulan en la década de 1570 (cuando coinciden las dificultades agrícolas, la peste, la subida de los encabezamientos y de la sal), y que proliferan luego de la implantación de los millones: J. E. Gelabert localiza varias protestas de feligresías rurales de la tierra de Santiago en las décadas de 1590 y 1620; en Pontevedra, el gremio de Mareantes, que afrontará en la segunda mitad del XVI el pago del 40-50 por 100 de las alcabalas que pesaban sobre la villa, acomete a inicios del XVII numerosos pleitos relacionados con la percepción de alcabalas y millones. En Vigo hubo diversas resistencias a pagar pedidos extraordinarios (1628, 1638, 1641, 1644); en Coruña, en 1663 , un tropel de mujeres encolerizadas acometió a los regidores proclamando que "malditos fuesen los regidores de la Coruña, que dejaban llevar la gente della a la campaña, y maldito fuese quien no los matase

${ }^{22}$ El rendimiento del estanco de la sal en la segunda mitad del XVI en M. ULLOA: La Hacienda Real, op. cit., pp. 395 y ss.; testimonios de numerosos pedidos extraordinarios en el curso del XVII en el Arch. Histórico Provincial de Orense, Municipal, Caja 120. 
donde pudiese" ${ }^{23}$. La propia Junta del Reino, dentro de su tradicional sumisión -o «nunca disputada obediencia y postrada resignación»mostrará en algunos momentos reticencias poco corrientes y serán continuas las quejas contra la exigencia de la Real Hacienda, tan numerosas que "en ellas se agotó el número de los vocablos de la lengua española», como exclamó escandalizado en 1669 el procurador de Betanzos ${ }^{24}$.

\section{IMPORTANCIA DE LOS MODOS DE REPARTO Y COBRANZA DE LAS RENTAS PROVINCIALES}

Para explicar las mayores o menores resistencias provocadas por la fiscalidad real no basta con conocer las cantidades que, en diversos momentos, ésta detrae; ha de averiguarse, también, su distribución en el interior del Reino, por actividades económicas y por contribuyentes, y las formas de recaudación. Es fundamental saber en qué medida los concejos a lo regimientos participan en la distribución y recaudación de las cargas.

En lo que respecta al reparto de las rentas provinciales entre las diferentes provincias del Reino ya resaltamos el carácter urbano de millones y alcabalas, y también su flexibilidad o acomodación a los cambios económicos que se van produciendo (desgravación de las provincias interiores; mayor presión fiscal en Santiago, Coruña, Betanzos y Tui). En los núcleos urbanos el reparto de alcabalas por miembros revela la escasa "base industrial" de Galicia; los gremios de artesanos aportan poca cosa, al lado de lo que supone la venta de vino y de paños, y de la diezma y la pesca en el litoral. Abordar problemas más concretos, referidos a las formas de reparto y recaudación en cada ciudad o villa encabezadas, requeriría mayor número de páginas del que disponemos. Anotemos tan sólo que, por la documentación que conocemos del AGS, Pontevedra, Lugo y Orense, una vez encabezadas, pueden acudir al

${ }^{23}$ Vid. J. E. Gelabert: Santiago..., op. cit., p. 135; M. a C. GonzAlez Muñoz: Vigo en su historia, Vigo 1980, pp. 166 y ss. y F. TETTAMANCY: Apuntes para la historia comercial de la ciudad de La Coruña, Coruña 1900, pp. 570-571.

${ }^{24}$ La actividad de la Junta en el xvII se estudia por M. ${ }^{a}$ L. Gonzalez Rios, Las Juntas del Reino de Galicia en el siglo XVII, Santiago 1986, ms. inédito. 
arriendo, al reparto más o menos negociado con los gremios, pueden combinar ambos sistemas o recurrir a la fieldad (que parece el sistema menos practicado). No faltan los compartos directos a toda o buena parte de la población: en Lugo, en 1542, se reparte directamente entre 163 cotizantes el 73 por 100 del encabezamiento; en Ribadavia, en 1591, la cantidad del encabezado la distribuyen también, nominalmente, entre todo el vecindario, personas nombradas por el concejo ${ }^{25}$. No es preciso insistir en la ventaja que para las poblaciones, y en particular para las oligarquias urbanas, supone el sistema de encabezamientos (generalizado en 1534-36), a la hora de decidir los sistemas de reparto y recaudación sin que intervenga una burocracia foránea (de aquí las diversidades que se notan entre unas y otras poblaciones, o en una misma a lo largo de varios años). Por lo que toca a los millones, ya antes de su encabezamiento son recaudados con intervención de las ciudades en su condición de "arqueras". Alcabalas y millones, por su carácter fundamentalmente urbano, son el reflejo de ciertas caracteristicas del poder de la monarquia de Antiguo Régimen: un poder que se ejerce mucho más en las ciudades y villas que en el mundo rural, más desgravado. Si la presión del fisco real es un índice de la mayor o menor incidencia del poder de la corona, habrá que convenir en que Galicia continúa siendo "periferia" de la corona de Castilla - y no sólo en el sentido geográfico- en el curso del XVI y XVII, y que esta condición periférica es evidente sobre todo en el mundo rural (cuya cultura, por lo demás, poco tenía que ver con la "oficial»).

El sistema de encabezamiento refleja también los límites del poder, que a falta de una burocracia suscribe conciertos con los concejos, se vale, en suma, de las estructuras políticas periféricas para cobrar no tanto "impuestos" como "tributos" (cobrados a comunidades que los reparten internamente) ${ }^{26}$. Insistimos, finalmente en que alcabalas y millones básicamente se recaudan sobre la venta y consumo de vino por menor, cosa que socialmente no deja de ser importante al tratarse de un producto cuyo consumo no era absolutamente vital. Quizá por ser el vino un producto muy gravado, su consumo se desplazó hacia los caldos más baratos, lo que explicaría la extensión de los viñedos próximos a Santiago y Coruña en el curso del XVII y la crisis y quejas continuas de Orense. El peso de la alcabala sobre los productos textiles de importación pudo provocar por su parte, el aumento de consumo de artículos de

\footnotetext{
25 AGS. EdH, Legs. 118 (Lugo) y 96 (Ribadavia).

${ }^{26}$ Sobre la cuestión, A. M. Hespanha: As vésperas..., op. cit., pp. 382.
} 
lino, de manufactura doméstica. El mundo rural está, salvo en el caso del servicio (en términos absolutos), mucho más aliviado, en parte por la dificultad de acomodar a las economias de autosubsistencia impuestos sobre tráfico de mercancias $y$, en el fondo, porque los campesinos hacen frente a otros "fiscos", que no son el real. De todas formas, como consumidores y vendedores de productos en el mercado urbano -textiles y sobre todo vino- contribuyen a pagar las alcabalas y millones de otros encabezamientos que no son los de sus partidos.

En las feligresías rurales las alcabalas y al principio también los millones - a veces hasta doblado el XVII- se repartían por capitación directa, salvo una corta cantidad o alcabala foránea (del 5 al $15 \%$ ). La distribución interna solía ajustarse, aunque la correlación no fuese total, a la fortuna de cada uno ${ }^{27}$. Los vecinos de la tierra de Monterroso senalaban en 1597 que el repartimiento se hacía entre ellos "cada uno conforme a su posibilidad (...), y hacen repartimiento entre si por dos hombres honrados nombrados por cada feligresía», los cuales "reparten a rico como rico y pobre como pobre, teniendo atención al que más vende, y esto se hace conforme a los tratos, cosechas, crianzas y labranzas que cada uno tiene". De manera parecida se expresan los vecinos de Borraxeiros y Ventosa que, en concejo, nombraban urepartidores y cogedores en cada feligresía, los cuales reparten conforme a las cédulas de repartimiento" - «hijuelas" o relaciones nominales de cotizantes-; un alcalde diputado del concejo llevaba luego los maravedís al tesorero real residente en Lugo ${ }^{28}$. El sistema fiscal, administrado por los vecinos, era relativamente barato pues los costes del reparto, recaudación y conducción del dinero a las tesorerías provinciales no suponían más del 5 por 100 de las cantidades estipuladas en el encabezamiento. La distribución de las cuotas no era tampoco tan arbitraria como hubiera podido creerse; cierto que no faltan los pleitos y juicios de residencia en los que se acuse a los oficiales locales, y en particular a los escribanos, de toda clase de abusos ${ }^{29}$. Pero el escalonamiento de las cuotas revela que se acomodaban en alguna medida a las fortunas. Este escalonamiento es muy grande: en la década de 1590 encontramos en Cervantes cuotas de

27 Vid. J. E. GelaberT: "Fuentes fiscales y estructura socioeconómica", en Actas /I Jornadas de Metodologia y Didáctica de la Historia, Cáceres 1982, con datos comparados sobre cuotas y fortunas rurales.

${ }^{29}$ AGS, ELH, Leg. 97.

${ }^{29}$ Algunas muestras en el Arch. del Reino de Galicia, Vecinos, Legs. 14936/3 (1602, varias feligresías próximas a Santiago); 3505/29 (1633, los "trabajadores" de la ciudad de Orense). 
alcabalas entre 17 y 680 mvs.; en Monterroso los tramos van de 4 a 510 mvs.; en varias parroquias mindonienses, de 8 a 1.020; en las feligresias rurales del corregimiento de Viveiro las cuotas del millón de 1594 oscilan de 17 a 1.632 mvs... En todos los partidos aparece siempre una minoría de grandes cotizantes que triplica o cuadruplica la cuota media. Cuando es posible localizar los inventarios de estos grandes cotizantes se ve que forman, al filo de 1600, un grupo de campesinos poderosos, que el reparto, en definitiva refleja niveles de fortuna ${ }^{30}$. Sabemos, incluso, por algún documento excepcional que en determinados concejos se efectuaban unos toscos compoix para acomodar a ellos los repartos de alcabalas; tal es lo que se desprende de un pleito habido en 1712-14 en la feligresía de Bangueses (Orense), cuando cuatro vecinos, por elección del concejo parroquial, llevaron a cabo una "revista» o evaluación de los bienes raíces de cada uno, para repartir a continuación, conforme a los resultados del compoix, la alcabala y demás tributos. La valoración ofrece datos de cada explotación, parcela a parcela. En el cuadro siguiente se pone de relieve la jerarquización económica existente en la feligresía, según el valor de las explotaciones, y la que resulta del reparto de la alcabala:

${ }^{30}$ Identificación de algunos de los mayores cotizantes, en P. SAAVEdRA: Economía, Politica..., op. cit., p. 601. Las cuotas anteriores en AGS, ELH, Leg. 97 (MoNTERROSo y CERVANTES) y en la monografía que acabamos de citar, pp. 501 y ss. 
CUADRO X. VALOR DE LAS EXPLOTACIONES, EN DUCADOS, EN LA FELIGRESÍA DE BANGUESES, 1712-14

VALOR DE LAS

EXPLOTACIONES EN DUCADOS
CASOS

$\%$

DUCADOS
$\%$

$\begin{array}{lrrrr}5-49 & 33 & 24,4 & 738 & 2,2 \\ 50-99 & 16 & 11,9 & 1.095 & 3,2 \\ 100-199 & 33 & 24,4 & 4.509 & 13,2 \\ 200-399 & 32 & 23,7 & 8.520 & 24,9 \\ 400-799 & 12 & 9 & 7.010 & 20,5 \\ 800-1599 & 6 & 4,4 & 5.750 & 16,8 \\ 1600-3000 & 3 & 2,2 & 6.547 & 19,2 \\ & 135 & 100 & 34.169 & 100\end{array}$

La jerarquía económica en el interior de la parroquia no precisa mayores comentarios: se evidencia en la valoración de las explotaciones, que van de 5 a 3.000 ducados, y en el reparto de las cuotas, de uno a más de 700 mvs. Hay, sin embargo, más cotizantes que explotaciones lo que puede deberse o bien a que se les impone alguna cantidad a los 
REPARTO DE LA ALCABALA EN LA FELIGRESÍA ANTERIOR

\begin{tabular}{lcccc}
\hline $1-24$ & 11 & 55,2 & 778 & 10,5 \\
$25-49$ & 30 & 18,2 & 1.044 & 14,1 \\
$50-99$ & 23 & 13,9 & 1.472 & 19,8 \\
$100-199$ & 15 & 9,1 & 2.116 & 28,5 \\
$200-399$ & 5 & 3 & 1.400 & 18,9 \\
$400-799$ & 1 & 0,6 & 612 & 8,2 \\
\hline $1-24$ & 165 & 100 & 7.422 & 100 \\
\hline
\end{tabular}

Fuente: Arch. Reino de Galicia, Vecinos, 19924/20.

forasteros que tienen bienes en la feligresía o, más bien, a que se reparte, en ciertos casos, más de una cuota por hogar, como sabemos por otras fuentes. En ciertos casos, los hijos que trabajan a jornal, los criados, el suegro y el yerno, cuando tienen bienes separados, cotizan aparte; tal es la razón por la cual a menudo $-\mathrm{y}$ aunque a primera vista pueda parecer sorprendente- se mencionen en las fuentes documentales más cotizantes que vecinos. Esto puede explicar que, porcentualmente, los pequeños cotizantes sean más numerosos que las pequeñas explotaciones. Dejemos, por otra parte, constancia de lo poco que supone la alcabala en 1712-1714 en esta parroquia concreta: 45 mvs., por cotizante, o 55 por explotación. La recuperación demográfica y agrícola de la segunda mitad del XVII (o un poco anterior en el litoral) es en alguna medida responsable de este "alivio" ${ }^{31}$.

${ }^{31}$ Esta tan reducida cuota media no ha de generalizarse, pues como sucedía en la 
Los encabezamientos no parecen haber beneficiado tan sólo a las oligarquías que ostentaban el poder en las principales ciudades y villas; los partidos rurales se aprovecharon también del sistema. La convicción, bastante extendida, de que las ciudades manipulaban el sistema fiscal y sobrecargaban alegremente los núcleos rurales precisa ser demostrada en cada caso. Recordemos, al respecto, que las ciudades cargan con un porcentaje muy elevado - progresivamente creciente- de alcabalas y millones; anotemos también que muchos repartos, implantados los encabezamientos, venían desglosados por partidos de la Contaduria de Hacienda - sin que el reparto quedase al arbitrio de la cabeza de provincia- y, en última instancia, los partidos o circunscripciones fiscales rurales podian quejarse a las oficiales del Consejo de Hacienda o a la propia, Real Audiencia de repartos abusivos. Nos parece que la autonomía de los partidos es cada vez mayor: en el curso del siglo XVII consiguen recaudar los millones mediante el arriendo de la taberna parroquial (a veces con oposición de la ciudad cabeza de provincia), y negocian los encabezamientos de alcabalas directamente con los oficiales de la Real Hacienda, o solicitan rebajas ${ }^{32}$. El sistema de encabezamientos "dinamizó" a los partidos rurales, pues era el propio concejo de vecinos el que nombraba repartidores y cogedores para cobrar una cantidad determinada. Todos se conocian, y no era fácil que se pudiesen cometer grandes abusos, aunque el analfabetismo, la incapacidad para leer y contar de la mayoría de los campesinos, podía propiciar manipulaciones en los repartos (es éste un aspecto capital, que hoy puede pasar fácilmente desapercibido). Es enormemente significativo a este respecto que en determinados concejos los repartos de alcabalas presentan un estadio más evolucionado" en los partidos de realengo que en aquéllos en donde estas rentas están enajenadas. Parecen poco importantes las alcabalas que la Hacienda Real tenía enajenadas en Galicia a mediados del XVIII. Si nos atenemos a las cifras de los resúmenes generales del Catastro, que engloba "alcabalas y oficios enajenados", ambos capitulos ascendian a 550.617 reales, el 14,7 del valor total de alcabalas y cientos, como señalamos atrás. Una parte de la cantidad anterior corresponde, sin embargo, al valor de los oficios, sin que en este momento nos sea posible

\footnotetext{
segunda mitad del XVI, también en el s. XVIII la presión del fisco real varia bastante de un partido a otro, como revela el Catastro de Ensenada (aunque ha de utilizarse con precaución, pues no siempre se declaran todas las rentas provinciales): en Mondoñedo hay parroquias que pagan $113 \mathrm{mvs}$./vecino mientras otras superan los $900 \mathrm{mvs}$./vecino.

${ }^{32}$ Ajuste estipulado directamente por vecinos nombrados en concejo abierto y por representantes de la Hacienda Real en los protocolos; i.e. Arch. Universidad de Santiago, Protocolos, Legs. 1962; 2785, numerosos fs, 2791, id. y 2413.
} 
individualizar unas y otras cantidades. Tan sólo a través de la consulta de los libros parroquiales del catastro o de las actas municipales pueden obtenerse conclusiones más precisas. Así, en Lugo estaban enajenadas alcabalas en pueblos, por valor de unos 55.000 rs. (el 18 por 100 del total provincial en 1780); y en Orense 53.000 rs. (el 9 por 100); en esta provincia el mayor beneficiario era el conde de Lemos, con 21.679,5 rs., seguido del Marqués de Malpica, con 18.482. Otro gran beneficiario de las alcabalas enajenadas, al lado del conde de Lemos, era en Galicia el arzobispo de Santiago: en 1773 percibía en tal concepto 59.477,3 rs. (lo que en la fecha suponía tan sólo un 2,8 por 100 de los ingresos de la mesa arzobispal) ${ }^{33}$. En algunas jurisdicciones del arzobispo las alcabalas se habian encabezado en la década de 1530; tal sucedió, por ejemplo, en la villa de Muros, en donde el arriendo mancomunado, tendente a evitar las pujas, parece haber sido la norma; igual en otras jurisdicciones del litoral, y aunque en algunos concejos la alcaba notó subidas, en otros hubo serias resistencias; asi, en la feligresía de San Julián de Poio los vecinos manifestaban en 1671 que estaban en posesión de pagar 151,5 ducados al año de alcabala, "sin que en tiempo alguno se hubiese arrendado ni puesto en postura", punto sobre el que quería innovar el arzobispo; hacia 1730 los vecinos de San Adrián y Santa Cristina, en la ría de Vigo, manifestaban también que venían pagando por razón de alcabala" una cuota fija por comparto, desde tiempo inmemorial, sin que jamás hubiese cabido puja ni novedad en dicha cuota». En repartos efectuados en Xallas en 1655-57 queda de manifiesto cómo la alcabala que percibe el arzobispo se distribuye según criterios más «arcaicos" o menos flexibles que en las tierras de realengo: el reparto se hace por "fogos", de forma que cada cotizante equivale a medio "fogo", un cuarto, etcétera (i.e., a un Cristóbal Alonso Pereiro se le carga la cuota de «medio fogo", y "que le ayude Juan Dalén con real y medio en el año", y así más casos) ${ }^{34}$. En muchas ocasiones, los vecinos parecen haber asimilado - en buena medida por interés - las alcabalas enajenadas a cualquier carga señorial, tratando de evitar aumentos y distribuyéndolas con criterios menos elásticos que en los partidos en los que la percibia el rey, y en donde el concejo debía negociar y nombrar repartidores de las can-

33 Para Orense, O. Gallego Domínguez, “Hacienda y fiscalidad en la Galicia del siglo XVIII", original mecanografiado que la autora nos facilitó amablemente; para Lugo, Arch. Histórico Provincial, Actas 67, y para las alcabalas del arzobispo de Santiago, Arch. Histórico Diocesano de Santiago, Fondo General, Leg. 44.

${ }^{34}$ Archivo Histórico Diocesano, Fondo General, Legs. 71-72, con amplia información sobre las alcabalas arzobispales, y Arch. Reino de Galicia, Vecinos, Leg. 14652/18 (repartos en Xallas). 
tidades encabezadas. En numerosos casos los vecinos de concejos con alcabalas enajenadas lograron ventajas: en varias jurisdicciones del arzobispo (Ribeira, Grove, Xallas, Melide, Montes, Tabeiros...) permanecen estancados de 1775 a 1796, cuando precisamente este impuesto nota subidas apreciables, $y$, lo que es más significativo, en determinadas jurisdicciones de la provincia de Lugo en las que las alcabalas estaban en manos de la nobleza su valor era a mediados del xVIII muy inferior al de los cientos, síntoma de que habían quedado estabilizadas en el curso del siglo XVI, pues en donde así no había sucedido alcabalas y cientos tenian en la época de realización de Catastro valores parecidos. En este aspecto, los vecinos de territorios de señorio obtuvieron algunas ventajas no siempre de simple gracia, sino a costa de resistirse a la modificación de una carga que ellos presentaban como otra cualquiera de tipo señorial.

En el curso del siglo XVIII el Reino de Galicia notó una progresiva mayor presión fiscal, en términos absolutos y relativos. La tendencia predominante a lo largo del XVI y XVII, que había conducido a que Galicia viese reducido el porcentaje que de las rentas provinciales le correspondía dentro de la corona de Castilla, se invirtió, lo que en parte - como advertimos antes- es el reflejo de las mayores potencialidades económicas de la periferia frente a un interior menos dinámico que en el XVI. En el cuadro siguiente se exponen las cantidades que Galicia paga en diversos momentos, y el porcentaje que representan con relación a la corona de Castilla. 


\section{CUADRO XI. VALOR DE LAS RENTAS PROVINCIALES EN GALICIA ${ }^{35}$}

\begin{tabular}{llcl}
\hline AÑO & $\begin{array}{c}\text { MILLONES } \\
\text { DE MRS }\end{array}$ & INDICE & $\begin{array}{c}\text { \% SOBRE EL TOTAL DE LA DE LA } \\
\text { CORONA DE CASTILLA }\end{array}$ \\
\hline 1712 & 149,8 & 100 & 6,2 \\
1722 & 175,5 & 117 & 6,7 \\
1749 & 205,8 & 137 & 7 \\
1755 & 230,85 & 154 & 7,2 \\
1780 & 267 & 178 & 8,3 \\
1787 & 344,4 & 230 & 8,3 \\
1792 & 446,9 & 298 & 8,8 \\
1827 & 314 & 210 & 10 \\
\hline
\end{tabular}

Fuente: M. Artola, La Hacienda, op. cit, pp. 303 y 353 para 1712, 1722, 1749, 1787 y 1792; DGR, 1. ${ }^{\mathrm{a}}$ R. Leg. 2153 y 2159 (1755 y 1780) y AHN, Hacienda, Leg. 1835 (1827).

Aunque el aumento fue inferior al de los precios de ninguna manera puede considerarse insignificante, sobre todo teniendo en cuenta que se acumula en la década de 1780-90, cuando aparecen algunas dificultades de tipo agrario. El valor de las rentas provinciales aumenta un 29 por 100 de 1780 a 1787; y un 30 de aquí a 1792. Sin embargo, las dificultades y descontento ocasionados por las rentas provinciales se debieron más a cambios en las formas de percepción que al aumento de las cantidades a cobrar (si bien no podrán separarse ambos hechos). En efecto, un decreto de $29-\mathrm{Vl}-1785$ ordenaba poner en administración las

${ }^{35}$ No se incluyen en la cifra de 1827 los derechos de puertas, que ascendían a 65,4 millones de maravedís. 
rentas, lo que significaba una auténtica novedad pues, con independencia de que a nivel de toda Galicia rigiese el arriendo o la administración directa (ligada ésta al establecimiento de Intendentes y subdelegados), los partidos habían continuado encabezándose. Desde 1785 las ciudades comienzan a luchar por obtener nuevos encabezamientos, pero las negociaciones fueron lentas y en 1790 no habian conseguido volver al sistema tradicional, pese a las promesas ${ }^{36}$.

El motín que a fines de 1790 se extiende por diversas partes de Lugo y Orense, y del que hasta el presente no se ha dado explicación alguna, está, -a no dudarlo, relacionado con la supresión de los encabezamientos y con la aparición en las ferias de una burocracia fiscal ocupada en la cobranza de impuestos. El asunto se agravaba si se tiene en cuenta que, en el curso del XVIII, habían aumentado considerablemente las ferias, y muchas habian surgido y se celebraban sin autorización de ningún tipo, por iniciativa de los vecinos, y eran francas, contratándose en aquellas sobre todo ganado, lienzos, herramientas y paños ${ }^{37}$. Los amotinados se dedicaban a provocar alborotos en las ferias, atacando a los recaudadores de impuestos. Las instrucciones del Real Acuerdo y del intendente a las justicias locales se orientan a insistirles en la obligación de mantener el orden en ferias y mercados y de recordar a los pueblos que deben pagar los derechos reales. En carta de 6-IV-1791 a la ciudad de Santiago, después de que en un incidente en una feria de Villalba hubiese muerto un amotinado y habido varios heridos, el Intendente señalaba que los encabezamientos habían de estipularse pueblo a pueblo y en su presencia ${ }^{38}$.

36 Archivo Histórico Provincial de Lugo, Actas, 75.

37 Una relación de las numerosísimas ferias y mercados de fines del XVIII en J. GARCiA LOMBARDERO: La agricultura y el estancamiento económico de Galicia en la España del Antiguo Régimen, Madrid 1973, apéndice III. Sobre las caracteristicas de cada mercado o feria, y en ocasiones sobre su fecha de fundación, hay datos importantes en J. LARRUGA, $t$. XLIII de sus Memorias, y expedientes de concesión en el AGS, DGR, 1. ${ }^{\text {a }}$. Legs. 2063, 2064 y 2065.

${ }^{38}$ Archiv. Municipal de Santiago, Consistorios, 1790 y 1791 , y Arch. Histórico Provincial de Lugo, Municipal, Actas, También los datos que aporta, con documentos originales, D. Juan M. DE Bedoya en su Retrato Histórico del Emm. Excmo. Señor D. Pedro Quevedo Quintano, Madrid 1835: La partida de Ulloa estaba formada por «un corto número de paisanos robustos armados por la mayor parte de palos, que presentándose en el paraje de la cuatropea de ferias tocando una cierta corneta o instrumento rústico alborotaban y espantaban el ganado vacuno, de cerda y caballos, introducian con esto la confusión, y mientras se desparramaban y corrían las gentes a defender y recoger sus animales, descargaban golpes sin piedad sobre los alcabaleros y dependientes de la Real Hacienda a la voz de 'viva el Rey y muera la Unica', robaban las cajas y administraciones y cometian otras diferentes tropelías. Esparcian, que en esto no obraban contra el rey, pues las nuevas 
El Gobierno sospechó que existian connivencias entre las oligarquías urbanas y los amotinados, y las cabezas de provincia recibieron orden del Real Acuerdo de averiguar, con auxilio militar y de las justicias locales, la identidad de "los ladrones y malhechores que infestan el Reino y se entran en las ferias a perturbar e impedir el sosiego de ellas". El Agente General del Reino en la Corte comunicó en diciembre de 1790 a la ciudad de Lugo que en Madrid existía la convicción de que todo el Reino de Galicia se hallaba alborotado y sublevado y que los motines se extendian a todo el país, con lo que corría serio peligro «el timbre que (el Reino) siempre había tenido de fidelísimo". El 18-XII-1790 la ciudad lucense le escribe al monarca, lamentando que en la corte se formasen tan mala opinión del reino de Galicia, cuando los «insultos" cometidos en las ferias to fueran por "dependientes de rentas provinciales, arrendatarios, gentes sediciosas, vagos, ociosos y aldeanos desconocidos»; en todo caso, añadian los regidores, todo se habría evitado si se pusiesen en práctica los encabezamientos negociados por las ciudades, lo que a la sazón aun no había tenido lugar, con lo cual los vecinos sufrían todos los inconvenientes de la administración directa. En carta de 5/III/ 1791 a la ciudad de Santiago, Orense consideraba también que, para evitar "que gima más tiempo este vecindario bajo la administración que sufre", era más urgente conseguir el encabezado que pedir la supresión de la contribución de Frutos Civiles (lo cual refleja la importancia que las oligarquías dan al encabezamiento, pues eran también, explicablemente, opuestas a los Frutos Civiles) ${ }^{39}$. En los años siguientes las rentas debieron encabezarse: en 1827, iban en administración un 26 por 100 y encabezados un 74 por 100 .

El motín de la Ulloa, el mayor movimiento antifiscal de la Galicia del Antiguo Régimen, pone asi de relieve que la incidencia de un sistema fiscal no deriva sólo de las cantidades que cobra, sino de la forma de cobrarlas. Aunque en la década de 1780 hubo alzas notables de las rentas provinciales, podrian buscarse en el XVI situaciones más graves en este aspecto; fue la supresión de los encabezamientos y la aparición

exacciones no procedian de la voluntad de S.M. sino de la rapacidad y abuso de los administradores y ministros de rentas reales, que se habian propuesto engrosar con la sangre de los pobres" (pp. 54-55). A través de la información que ofrece Bedoya -y sobre cuya pista nos puso $X$. R. BARREIRO FERnÁNDEZ - puede colegirse que en casos concretos los amotinados fueron más allá de las simples protestas antifiscales, pero no podemos ahora detenernos en ello.

${ }^{39}$ Arch. Histórico Provincial de Lugo, Municipal, Actas, 75 y Arch. Municipal de Santiago, Consistorios, 1791. 
de una burocracia fiscal lo que encrespó el ánimo de las oligarquias y también de muchos campesinos, pues el sistema de encabezamientos no había sido gestionado tan sólo por las oligarquías urbanas, sino también por los vecinos representantes de los concejos o "partidos» rurales; el "Contrato recíproco" en que se basaba el sistema de encabezamiento quedaba roto unilateralmente, o por decisión, según los amotinados, no del rey -que no podía ser tan perverso- sino de los ministros de las rentas reales que se habian propuesto, según una imagen clásica en los motines antifiscales, engordar con la sangre de los pobres. Era, por tanto, justo alzarse contra las "malvadas sanguijuelas" que explotaban a tan leales vasallos de S. Mgd. 